\title{
The epicardial fat thickness is associated with fragmented QRS in patients with newly diagnosed metabolic syndrome
}

\author{
Tayyar Akbulut ${ }^{1} \odot$, Faysal Şaylık ${ }^{1 *} \odot$, Cihan Sุengül ${ }^{1} \oplus$
}

\section{SUMMARY}

OBJECTIVE: The metabolic syndrome involves both metabolic and cardiovascular risk factors and is associated with cardiovascular mortality. Epicardial fat tissue plays a crucial role in deleterious effects of metabolic syndrome on the heart, including myocardial fibrosis. The fragmented QRS reflects heterogeneous depolarization of the myocardium and occurs as a result of fibrosis. Thus, we aimed to investigate whether there is an association between fragmented QRS and epicardial fat tissue in patients with metabolic syndrome.

METHODS: This study enrolled 140 metabolic syndrome patients, of whom 35 patients with fragmented QRS (+) and 105 patients with fragmented QRS (-). The two groups were compared with respect to clinical, laboratory, electrocardiographic, and echocardiographic indexes.

RESULTS: Fragmented QRS (+) patients had higher waist circumference, red cell distribution width, creatinine, left ventricular end-systolic diameter, left atrium diameter, septal a velocity, QRS duration, and epicardial fat tissue compared with fragmented QRS (-) patients. Waist circumference, red cell distribution width, QRS duration, left ventricular end-systolic diameter, left atrium diameter, septal a velocity, and epicardial fat tissue were significantly associated with the presence of fragmented QRS. The QRS duration and epicardial fat tissue were independently associated with the presence of fragmented QRS on surface electrocardiographic in metabolic syndrome patients.

CONCLUSIONS: Epicardial fat tissue and QRS duration were independently associated with the presence of fragmented QRS. Basic echocardiographic and electrocardiographic parameters might be used for the risk stratification in metabolic syndrome patients.

KEYWORDS: Electrocardiography. Echocardiography. Metabolic syndrome.

\section{INTRODUCTION}

The metabolic syndrome (MetS), a clustering of metabolic and cardiovascular risk factors, contributes considerably to cardiovascular mortality ${ }^{1}$. Visceral obesity seems to play a key role in the development of all features of Met $\mathrm{S}^{2}$. Epicardial fat tissue (EFT) is in direct contact with the myocardium, and it is very active metabolically. Recent studies have suggested that EFT with both local and systemic effects has an important role in deleterious effects of MetS on the heart ${ }^{3,4}$. In addition to its association with atherosclerosis, hypertension, and diabetes, new data suggest that MetS is also strongly associated with cardiac arrhythmias ${ }^{5}$. The MetS and EFT appear to associate with multiple electrocardiographic (ECG) abnormalities and cardiac arrhythmias ${ }^{6}$. In this context, previous studies have shown the association of EFT with ECG abnormalities, such as atrial fibrillation (AF), P-wave dispersion, QRS prolongation, QT prolongation, left axis deviation, ST-T wave abnormalities, and extrasystoles in patients with Met $S^{7,8}$. Recent interest has focused on fragmented QRS (fQRS) as a novel resting ECG parameter. The fQRS, defined as the presence of R' wave or notching of $\mathrm{R}$ or $\mathrm{S}$ patterns with or without $\mathrm{Q}$ waves on a 12-lead ECG, has been shown to reflect heterogeneous depolarization of the ventricular myocardium that can occur due to ischemia, fibrosis, or scar ${ }^{9,10}$. Although a recently published study has shown that fQRS is associated with left ventricular dysfunction in patients with Met $S^{11}$, to the best of our knowledge, there is no study showing the relationship between fQRS, visceral fat, and MetS. In the present study, we examined the association of fQRS with EFT in newly diagnosed MetS subjects.

\section{METHODS}

\section{Study population}

$\mathrm{Met} S$ was diagnosed based on the concomitant presence of three or more risk factors established by the NCEP ATP III 2005 guidelines: systolic blood pressure (SBP) and diastolic blood pressure (DBP) $\geq 130$ and $\geq 85 \mathrm{mmHg}$, respectively, fasting plasma glucose $\geq 100 \mathrm{mg} / \mathrm{dL}$, waist circumference (WC) $>102 \mathrm{~cm}$ for men and $>88 \mathrm{~cm}$ for women, fasting triglycerides $>150 \mathrm{mg} / \mathrm{dL}$, and high-density lipoprotein cholesterol $<40 \mathrm{mg} / \mathrm{dL}$ for men and $<50 \mathrm{mg} / \mathrm{dL}$ for women ${ }^{12}$. Notably, 140 patients with newly diagnosed MetS constituted the final study population.

${ }^{1}$ Van Training and Research Hospital, Department of Cardiology - Van, Turkey.

${ }^{*}$ Corresponding author: faysalsaylik@gmail.com

Conflicts of interest: the authors declare there is no conflicts of interest. Funding: none.

Received on October 24, 2021. Accepted on December 05, 2021. 
A history of coronary artery or valvular heart disease, systolic heart failure (left ventricular ejection fraction $<50 \%$ ), diabetes mellitus, chronic liver or renal disease, hypothyroidism or hyperthyroidism, use of antihypertensive drug, statin, regular alcohol intake, drug abuses, QRS duration $>120 \mathrm{~ms}$, and incomplete or complete right and left bundle branch block were excluded. The Ethics Committee of Health Science University Van Education and Research Hospital approved the protocol.

\section{Electrocradiography}

Standard 12-lead surface resting ECGs (filter range, 0.5$150 \mathrm{~Hz}, 25 \mathrm{~mm} / \mathrm{s}, 10 \mathrm{~mm} / \mathrm{mV}$ ) were recorded for all the study population. Heart rate (HR) and QRS duration were noted. The fQRS was defined by the presence of various RSR' patterns (QRS duration <120 ms) with or without $Q$ wave, which includes an additional $\mathrm{R}$ wave ( $\mathrm{R}$ ') or notching of the $\mathrm{R}$ wave or $\mathrm{S}$ wave, or the presence of more than one $\mathrm{R}$ ' fragmentation without typical bundle branch block in two contiguous leads ${ }^{13}$. The standard 12-lead ECG was analyzed without using any magnification.

\section{Echocardiography}

Standard parasternal and apical views were obtained in the left lateral decubitus position by using a Vivid 3 Pro ultrasound machine (GE Vingmed Ultrasound, Milwaukee, WI, USA). The left ventricular ejection fraction (EF), interventricular septum thickness (IVST), and posterior wall thickness (PWT) were measured on M-mode traces recorded in the parasternal long-axis view. Mitral inflow was assessed from the apical four-chambered view with pulsed-wave Doppler by placing a 1-2 $\mathrm{mm}$ sample volume between the tips of the mitral leaflets during diastole. EFT was measured according to the previously described method ${ }^{2}$. EFT was identified as the echo-free space between the outer wall of the myocardium and the visceral layer of the pericardium at end-diastole in three cardiac cycles. The maximum EFT was measured at the point on the free wall of the right ventricle along the midline of the ultrasound beam, perpendicular to the aortic annulus. For the midventricular parasternal short-axis assessment, maximum EFT was measured on the free wall of the right ventricle along the midline of the ultrasound beam, perpendicular to the interventricular septum at midchordal and the tip of the papillary muscle level, as the anatomic landmark. The maximum value at any site was measured and the average value was calculated. Measurements were done according to established standards ${ }^{14}$.

\section{Statistical analysis}

Continuous variables were presented as mean \pm standard deviation or median [interquartile range (IQR)], and categorical variables were expressed as number and percentage. The KolmogorovSmirnov test was used to identify the normally distributed variables. The continuous variables were compared across the groups using Student's t-test or the Mann-Whitney U test. The categorical variables were compared using the chi-square test. The correlation between fQRS and EFT was calculated using point-biserial correlation analysis. To determine the independent predictors of fQRS, multivariable logistic regression analysis was performed. Due to the small number of dependent variables (number of fQRS $(+$ ) patients=35), we calculated Firth's penalized likelihood bias reduction in logistic regression analysis to avoid overfitting using R-software version 3.6.3 (R statistical software, Institute for Statistics and Mathematics, Vienna, Austria). Variables that were found statistically significant in the univariate analysis were entered in the multivariable logistic regression model. All data were analyzed using SPSS version 16.0 for Windows (SPSS Inc., Chicago, IL, USA). A p-value $<0.05$ was considered statistically significant.

\section{RESULTS}

The comparison of demographic, biochemical, clinical, ECG, and echocardiographic parameters is shown in Table 1. Weight, WC, red cell distribution width (RDW), rate of insulin use, and creatinine were significantly higher in Group 1 compared with Group 2. QRS (105 vs. 86 ms, $\mathrm{p}<0.001$ ), LA ( 41 vs. $39 \mathrm{~mm}, \mathrm{p}=0.001$ ), left ventricular end-systolic diameter (LVESD) (29 vs. $28 \mathrm{~mm}, \mathrm{p}=0.022$ ), septal a velocity ( 11 vs. $10, \mathrm{p}=0.011$ ), DT ( 200 vs. $180, \mathrm{p}=0.038$ ), and EFT $(9.96 \pm 1.38 \mathrm{~mm}$ vs. $7.34 \pm 1.03 \mathrm{~mm}, \mathrm{p}<0.001)$ were significantly higher in Group 1 compared with Group 2. EFT was significantly correlated with fQRS $(\mathrm{r}=0.556, \mathrm{p}<0.001)$ (Figure 1). WC, RDW, QRS, LVESD, LA, septal a velocity, and EFT were significantly associated with the presence of fQRS in univariable logistic regression analysis. Multivariable logistic regression analysis with variables that exhibit statistical significance in univariable regression showed that only QRS duration [odds ratio $(\mathrm{OR})=1.166, \mathrm{p}<0.001$ ] and EFT $(\mathrm{OR}=3.441, \mathrm{p}=0.002)$ were independent predictors of the presence of fQRS (Table 2).

\section{DISCUSSION}

In this study, fQRS(+) patients had higher EFT and QRS duration compared with fQRS(-) patients. Furthermore, EFT and 
Table 1. Demographic, clinical, laboratory, electrocardiographic, and echocardiographic indexes between fragmented QRS(+) and fragmented QRS(-) metabolic syndrome patients.

\begin{tabular}{|c|c|c|c|}
\hline Variables & $f Q R S(+)(n=35)$ & fQRS(-) (n=105) & p-value \\
\hline Age, years) & $56 \pm 7.54$ & $56 \pm 7.56$ & 0.985 \\
\hline Gender, n (\%) & & & 0.077 \\
\hline Male & $20(57.1)$ & $42(40)$ & \\
\hline Female & $15(42.9)$ & $63(60)$ & \\
\hline $\mathrm{BMI}, \mathrm{kg} / \mathrm{m}^{2}$ & $33.2(30.3-39.3)$ & $32.4(29.8-35.1)$ & 0.092 \\
\hline Height, m & $1.66 \pm 0.09$ & $1.63 \pm 0.07$ & 0.13 \\
\hline Weight, kg & $90(86-105)$ & $86(81-90)$ & 0.031 \\
\hline Waist circumference, $\mathrm{cm}$ & $105(95-115)$ & $98(92-104)$ & 0.014 \\
\hline Systolic BP, mmHg & $140(140-160)$ & $140(135-150)$ & 0.218 \\
\hline Diastolic BP, mmHg & $85(85-90)$ & $85(85-90)$ & 0.119 \\
\hline Diabetes mellitus, n (\%) & $33(94.3)$ & $88(83.8)$ & 0.157 \\
\hline Hypertension, n (\%) & $31(88.6)$ & $95(90.5)$ & 0.749 \\
\hline CAD, n (\%) & $6(17.1)$ & $15(14.3)$ & 0.682 \\
\hline History of familial CAD, n (\%) & $10(28.6)$ & $32(30.5)$ & 0.831 \\
\hline Cigarette smoking, n (\%) & $16(45.7)$ & $40(38.1)$ & 0.426 \\
\hline $\mathrm{CHF}, \mathrm{n}(\%)$ & $2(5.7)$ & $4(3.8)$ & 0.64 \\
\hline Atrial fibrillation, n (\%) & $\mathrm{O}(0)$ & $1(1)$ & 1.000 \\
\hline Thyroid dysfunction, n (\%) & $3(8.6)$ & $5(4.8)$ & 0.412 \\
\hline PAD, n (\%) & $0(0)$ & $4(3.8)$ & 0.572 \\
\hline Hyperlipidemia, n (\%) & $27(77.1)$ & $80(76.2)$ & 0.908 \\
\hline \multicolumn{4}{|l|}{ Use of drugs, n (\%) } \\
\hline Aspirin & $16(45.7)$ & $49(46.7)$ & 0.922 \\
\hline Calcium channel blockers & $14(40)$ & 35 (33.3) & 0.474 \\
\hline Beta blockers & 12 (34.3) & 35 (33.3) & 0.918 \\
\hline Insulin & $10(28.6)$ & $12(11.4)$ & 0.016 \\
\hline Oral antidiabetic & $33(94.3)$ & $86(81.9)$ & 0.076 \\
\hline Anti-hyperlipidemic & $16(45.7)$ & $49(46.7)$ & 0.922 \\
\hline \multicolumn{4}{|l|}{ Laboratory parameters } \\
\hline White blood cell, $\times 10^{3} / \mu \mathrm{L}$ & $8.46(6.7-11.5)$ & $7.58(6.9-9.8)$ & 0.329 \\
\hline Hemoglobin, g/dL & $15.1(12.9-15.9)$ & $14.8(13.3-15.7)$ & 0.985 \\
\hline RDW, fL & $45.4(42.7-49.7)$ & $41.7(39.7-44.5)$ & $<0.001$ \\
\hline $\mathrm{CRP}, \mathrm{mg} / \mathrm{dL}$ & $6.09(3.27-12.3)$ & $6.23(3-10)$ & 0.195 \\
\hline $\mathrm{TSH}, \mathrm{mIU} / \mathrm{L}$ & $1.65(1.18-2.8)$ & $1.8(1.18-2.34)$ & 0.883 \\
\hline Fasting insulin, mIU/L & $26(14.8-36.1)$ & $20.8(14-29.2)$ & 0.424 \\
\hline HOMA-IR & $9.19(4.09-15.8)$ & $6.99(4.11-12.95)$ & 0.412 \\
\hline $\mathrm{HbA1c} \%$ & $8.1(7.3-10.2)$ & $7.3(6.7-9.1)$ & 0.074 \\
\hline Fasting glucose, mg/dL & $145(121-206)$ & $133(107-213)$ & 0.349 \\
\hline BUN, mg/dL & $34.6(30.9-49)$ & $32(24-41)$ & 0.013 \\
\hline Creatinine, mg/dL & $0.89(0.82-1.04)$ & $0.76(0.61-0.91)$ & 0.001 \\
\hline Albumin, g/dL & $4.62(4.25-4.93)$ & $4.53(4.3-4.67)$ & 0.199 \\
\hline Triglycerides, mg/dL & $173(105-213)$ & $178(136.4-237)$ & 0.35 \\
\hline $\mathrm{HDL}, \mathrm{mg} / \mathrm{dL}$ & $36(34-39.1)$ & $37.3(32-41)$ & 0.975 \\
\hline $\mathrm{LDL}, \mathrm{mg} / \mathrm{dL}$ & $111.1 \pm 35.7$ & $112.4 \pm 38.5$ & 0.921 \\
\hline Total cholesterol, mg/dL & $193.8(178.6-219)$ & $196(161.2-221)$ & 0.885 \\
\hline \multicolumn{4}{|l|}{ ECG parameters } \\
\hline ECG rate, /s & $80.1 \pm 15.8$ & $80.6 \pm 10.9$ & 0.899 \\
\hline QRS, ms & $105(103-120)$ & $86(80-93)$ & $<0.001$ \\
\hline \multicolumn{4}{|l|}{ Echocardiographic parameters } \\
\hline $\mathrm{EF}, \%$ & $60(60-65)$ & $60(60-65)$ & 0.424 \\
\hline IVS, cm & $1.3(1.2-1.4)$ & $1.3(1.2-1.4)$ & 0.206 \\
\hline
\end{tabular}


Table 1. Continuation.

\begin{tabular}{l|c|c|c}
\hline Variables & fQRS(+) (n=35) & fQRS(-) (n=105) & $\mathbf{p}$-value \\
\hline LVEDD, $m m$ & $54(50-56)$ & $52(48-55)$ & 0.146 \\
\hline LVESD, $m m$ & $29(28-38)$ & $28(28-30)$ & 0.022 \\
\hline LA, mm & $41(40-43)$ & $39(36-42)$ & 0.001 \\
\hline E wave & $0.6(0.5-0.8)$ & $0.6(0.5-0.7)$ & 0.424 \\
\hline A wave & $0.9(0.7-0.9)$ & $0.8(0.7-0.9)$ & 0.422 \\
\hline Lateral e & $9(8-10)$ & $9(7-11)$ & 0.855 \\
\hline Septal e & $8(7-9)$ & $8(6-10)$ & 0.096 \\
\hline Lateral a & $13(11-15)$ & $12(9-14)$ & 0.011 \\
\hline Septal a & $11(10-12)$ & $10(8-11)$ & 0.238 \\
\hline IVRT & $110.9 \pm 14.1$ & $107.2 \pm 15.2$ & 0.038 \\
\hline DT & $200(166-220)$ & $180(150-200)$ & $<.34 \pm 1.03$ \\
\hline Epicardial fat thickness, mm & $9.96 \pm 1.38$ & 0.001 \\
\hline
\end{tabular}

BMI: body mass index; BP: blood pressure; CAD: coronary artery disease; CHF: congestive heart failure; PAD: peripheral artery disease; RDW: red-cell distribution width; CRP: C-reactive protein; TSH: thyroid-stimulating hormone; HOMA: homeostatic model assessment for insulin resistance; BUN: blood urea nitrogen; HDL: high-density cholesterol; LDL: low-density cholesterol; ECG: electrocardiography; EF: ejection fraction; IVS: interventricular septum; LVEDD: left ventricular end-diastolic diameter; LVESD: left-ventricular end-systolic diameter; LA: left atrium; IVRT: isovolumetric relaxation time; DT: deceleration time.

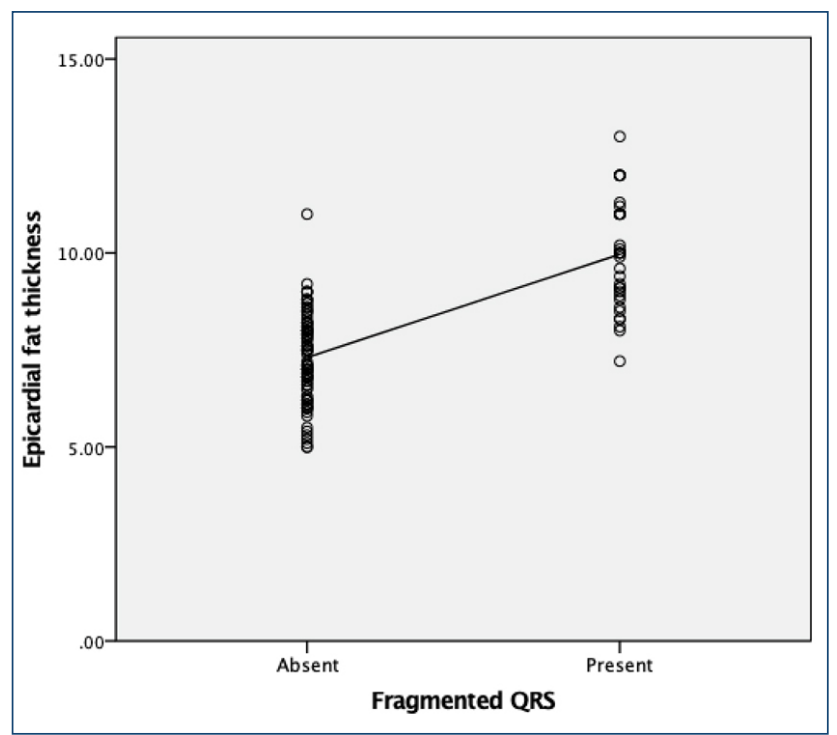

Figure 1. The correlation of epicardial fat thickness with fragmented QRS.

QRS duration were independent predictors of the presence of $\mathrm{fQRS}$ in MetS patients. These findings may support the thesis that at least some of the effects of MetS on cardiovascular diseases may be due to the accumulation of fat around the heart.

The EFT is in direct contact with the myocardium, and it is very metabolically active. The epicardial adipocytes can secrete a large number of cytokines and vasoactive peptides, including free fatty acids, interleukin- 6 , tumor necrosis factor- $\alpha$, angiotensin II, and plasminogen activator inhibitor- $1^{15}$. Recent studies have suggested that EFT with both local and systemic effects has an important role in deleterious effects of MetS on the heart ${ }^{3,4}$. Although the underlying mechanism is not clear exactly, EFT has also been shown to be associated with some ECG findings, such as AF, QT prolongation, left axis deviation, and low voltage in patients with MetS ${ }^{6}$. Obesity, hypertension, low-grade inflammation, oxidative stress, structural remodeling, and electrophysiological remodeling were all the proposed mechanisms ${ }^{16}$. However, the recent studies focus on myocardial fibrosis, which is the key histological component of cardiac remodeling in this context. Myocardial fibrosis, either in the form of interstitial, patchy, or dense scars, is shown to constitute a key histological substrate of arrhythmias ${ }^{17}$. Myocardial fibrosis is a well-recognized cause of morbidity and mortality ${ }^{18}$. Fibrotic scars of the cardiac muscle most commonly occur after myocardial infarction; however, there are various other conditions promoting myocardial fibrosis, such as hypertensive heart disease, diabetic hypertrophic cardiomyopathy, and idiopathic dilated cardiomyopathy ${ }^{19}$.

The recent data have suggested that EFT, through its capacity to produce and secrete adipo-fibrokines (pro-fibrotic molecules) such as Activin A and MMP8, could be a complementary mechanism contributing to the formation of myocardial fibrosis ${ }^{20}$. Interestingly, a magnetic resonance imaging (MRI) study by NG has demonstrated that increased EFT volume index is independently associated with increased myocardial fat accumulation and interstitial myocardial fibrosis ${ }^{21}$. Myocardial fibrosis is a well-known underlying mechanism of fQRS occurrence in various cardiac pathologies ${ }^{13}$. Bekar et al. demonstrated fQRS as an independent predictor of EFT in hypertensive patients in their recent study ${ }^{22}$. Yaman et al. showed that the presence of fQRS was associated with increased EFT in healthy population ${ }^{23}$. In the light of these data, we 
Table 2. Univariable and multivariable logistic regression analysis for detecting fragmented QRS.

\begin{tabular}{|c|c|c|c|c|}
\hline Variables & $\begin{array}{l}\text { Univariable OR } \\
(95 \% \mathrm{CI})\end{array}$ & p-value & Multivariable OR $(95 \% \mathrm{Cl})$ & p-value \\
\hline Gender, male & $0.500(0.230-1.085)$ & 0.08 & - & - \\
\hline BMI & $1.084(0.999-1.177)$ & 0.054 & - & - \\
\hline Waist circumference & $1.057(1.018-1.097)$ & 0.004 & $0.987(0.909-1.071)$ & 0.748 \\
\hline Systolic BP & $1.027(0.996-1.059)$ & 0.09 & - & - \\
\hline Diastolic BP & $1.096(0.987-1.216)$ & 0.086 & - & - \\
\hline RDW & $1.266(1.127-1.422)$ & $<0.001$ & $1.033(0.840-1.270)$ & 0.758 \\
\hline $\mathrm{HbA1c}$ & $1.129(0.935-1.363)$ & 0.207 & - & - \\
\hline BUN & $1.008(0.994-1.022)$ & 0.270 & - & - \\
\hline Creatinine & $2.672(0.958-7.451)$ & 0.060 & - & - \\
\hline QRS & $1.344(1.196-1.510)$ & $<0.001$ & $1.166(1.076-1.264)$ & $<0.001$ \\
\hline LVESD & $1.080(1.001-1.164)$ & 0.046 & $0.960(0.813-1.134)$ & 0.631 \\
\hline LA & $1.159(1.043-1.287)$ & 0.006 & $0.947(0.785-1.143)$ & 0.573 \\
\hline Lateral a & $1.136(0.978-1.273)$ & 0.103 & - & - \\
\hline Septal a & $1.247(1.049-1.483)$ & 0.012 & $0.909(0.657-1.256)$ & 0.562 \\
\hline DT & $1.008(0.997-1.018)$ & 0.152 & - & - \\
\hline Epicardial fat thickness & 7.553 (3.484-16.373) & $<0.001$ & $3.441(1.593-7.432)$ & 0.002 \\
\hline
\end{tabular}

BMI: body mass index; BP: blood pressure; RDW: red cell distribution width; BUN: blood urea nitrogen; LVESD: left ventricular end-systolic diameter; LA: left atrium; DT: deceleration time. Bold values indicate statistically significance $(p<0.05)$.

speculate that increased epicardial fat content and its relation to myocardial fibrosis may explain the association of EFT with $\mathrm{fQRS}$ in subjects with MetS as demonstrated in the present study. Another interesting and important finding of our study is that it emphasizes the importance of the location of ectopic fat accumulation. WS is the major criteria of MetS and is used widely to assess visceral adiposity. In concordance with some relatively old trials that showed WS as a stronger cardiovascular risk predictor than body mass index $(\mathrm{BMI})^{24}$, the present study showed that $\mathrm{fQRS}(+)$ patients had higher WC and EFT than fQRS(-) patients, and both EFT and WC but not BMI were significantly associated with the presence of fQRS in subjects with MetS. These findings might suggest that information about ectopic fat distribution may provide important insights into metabolic and cardiovascular disease risk. Although WC lost its importance in multivariable logistic regression analysis, the small event size might contribute to this result and further studies with a large sample size might shed more light on this issue.

\section{Limitations}

Firstly, the small sample size was the major limitation. Secondly, we did measure EFT by echocardiography, but we did not measure any surrogate of myocardial fibrosis. We can only speculate about EFT's possible impacts on myocardial fibrosis and fQRS. In order to better understand the role of EFT in this process, MRI studies measuring both myocardial fat content and fibrosis are needed in subjects with MetS. The strength of the current study is that basic echocardiography and ECG may help risk stratification of newly diagnosed subjects with MetS by EFT and fQRS. Further studies with larger sample size could be more definitive about this issue.

\section{CONCLUSIONS}

The present study demonstrated the association of EFT with fQRS in subjects with newly diagnosed MetS. Basic echocardiography and ECG may help in risk stratification in subjects with newly diagnosed MetS.

\section{AUTHORS' CONTRIBUTIONS}

FŞ, TA, CŞ: Conceptualization. FŞ, TA: Data curation, Investigation. FŞ: Software, Validation, Formal Analysis, Writing - review \& editing, Visualization. FŞ, CŞ: Methodology, Supervision, Writing - original draft. 


\section{REFERENCES}

1. Lakka HM, Laaksonen DE, Lakka TA, Niskanen LK, Kumpusalo E, Tuomilehto J, et al. The metabolic syndrome and total and cardiovascular disease mortality in middle-aged men. JAMA. 2002;288(21):2709-16. https://doi.org/10.1001/jama.288.21.2709

2. lacobellis G, Ribaudo MC, Assael F, Vecci E, Tiberti C, Zappaterreno $A$, et al. Echocardiographic epicardial adipose tissue is related to anthropometric and clinical parameters of metabolic syndrome: a new indicator of cardiovascular risk. J Clin Endocrinol Metab. 2003;88(11):5163-8. https://doi.org/10.1210/jc.2003-030698

3. Mahabadi AA, Massaro JM, Rosito GA, Levy D, Murabito JM, Wolf PA, et al. Association of pericardial fat, intrathoracic fat, and visceral abdominal fat with cardiovascular disease burden: the Framingham Heart Study. Eur Heart J. 2009;30(7):850-6. https:// doi.org/10.1093/eurheartj/ehn573

4. Silaghi A, Piercecchi-Marti MD, Grino M, Leonetti G, Alessi MC, Clement K, et al. Epicardial adipose tissue extent: relationship with age, body fat distribution, and coronaropathy. Obesity. 2008;16(11):2424-30. https://doi.org/10.1038/oby.2008.3793

5. Kurl S, Laaksonen DE, Jae SY, Mäkikallio TH, Zaccardi F, Kauhanen $J$, et al. Metabolic syndrome and the risk of sudden cardiac death in middle-aged men. Int J Cardiol. 2016;203:792-7. https://doi. org/10.1016/j.ijcard.2015.10.218

6. Granér M, Pentikäinen MO, Siren R, Nyman K, Lundbom J, Hakkarainen A, et al. Electrocardiographic changes associated with insulin resistance. Nutr Metab Cardiovasc Dis. 2014;24(3):315-20. https://doi.org/10.1016/j.numecd.2013.09.013

7. Elffers TW, de Mutsert R, Lamb HJ, Maan AC, Macfarlane PW, Willems van Dijk K, et al. Association of metabolic syndrome and electrocardiographic markers of subclinical cardiovascular disease. Diabetol Metab Syndr. 2017;9:40. https://doi.org/10.1186/ s13098-017-0238-9

8. Ebong IA, Bertoni AG, Soliman EZ, Guo M, Sibley CT, Chen YD, et al. Electrocardiographic abnormalities associated with the metabolic syndrome and its components: the multi-ethnic study of atherosclerosis. Metab Syndr Relat Disord. 2012;10(2):92-7. https://doi.org/10.1089/met.2011.0090

9. Das MK, Michael MA, Suradi H, Peng J, Sinha A, Shen C, et al. Usefulness of fragmented QRS on a 12-lead electrocardiogram in acute coronary syndrome for predicting mortality. Am J Cardiol. 2009;104(12):1631-7. https://doi.org/10.1016/j. amjcard.2009.07.046

10. Pei J, Li N, Gao Y, Wang Z, Li X, Zhang Y, et al. The J wave and fragmented QRS complexes in inferior leads associated with sudden cardiac death in patients with chronic heart failure. Europace. 2012;14(8):1180-7. https://doi.org/10.1093/ europace/eur437

11. Bayramoğlu A, Taşeolar H, Bektaş O, Yaman M, Kaya Y, Özbilen M, et al. Association between metabolic syndrome and fragmented QRS complexes: speckle tracking echocardiography study. J Electrocardiol. 2017;50(6):889-93. https://doi.org/10.1016/j. jelectrocard.2017.06.020
12. Grundy SM, Cleeman JI, Daniels SR, Donato KA, Eckel RH, Franklin $\mathrm{BA}$, et al. Diagnosis and management of the metabolic syndrome: An American Heart Association/National Heart, Lung, and Blood Institute scientific statement. Curr Opin Cardiol. 2006;21(1):1-6.

13. Supreeth RN, Francis J. Fragmented QRS - Its significance. Indian Pacing Electrophysiol J.2020;20(1):27-32. https://doi.org/10.1016/j. ipej.2019.12.005

14. Henry WL, DeMaria A, Gramiak R, King DL, Kisslo JA, Popp RL et al. Report of the American Society of Echocardiography Committee on nomenclature and standards in two-dimensional echocardiography. Circulation. 1980;62(2):212-7. https://doi. org/10.1161/01.cir.62.2.212

15. lacobellis $G$, Barbaro $G$. The double role of epicardial adipose tissue as pro- and anti-inflammatory organ. Horm Metab Res. 2008;40(7):442-5. https://doi.org/10.1055/s-2008-1062724

16. Watanabe H, Tanabe N, Watanabe T, Darbar D, Roden DM, Sasaki S, et al. Metabolic syndrome and risk of development of atrial fibrillation: the Niigata preventive medicine study. Circulation. 2008;117(10):1255-60. https://doi.org/10.1161/ CIRCULATIONAHA.107.744466

17. Nguyen TP, Qu Z, Weiss JN. Cardiac fibrosis and arrhythmogenesis: the road to repair is paved with perils. J Mol Cell Cardiol. 2014;70:8391. https://doi.org/10.1016/j.yjmcc.2013.10.018

18. Murtha LA, Schuliga MJ, Mabotuwana NS, Hardy SA, Waters DW, Burgess JK, et al. The processes and mechanisms of cardiac and pulmonary fibrosis. Front Physiol. 2017;8:777. https://doi. org/10.3389/fphys.2017.00777

19. Hinderer S, Schenke-Layland K. Cardiac fibrosis - a short review of causes and therapeutic strategies. Adv Drug Deliv Rev. 2019;146:7782. https://doi.org/10.1016/j.addr.2019.05.011

20. Venteclef N, Guglielmi V, Balse E, Gaborit B, Cotillard A, Atassi F, et al. Human epicardial adipose tissue induces fibrosis of the atrial myocardium through the secretion of adipo-fibrokines. Eur Heart J. 2015;36(13):795-805. https://doi.org/10.1093/eurheartj/eht099

21. Ng ACT, Strudwick M, van der Geest RJ, Ng ACC, Gillinder L, Goo SY, et al. Impact of epicardial adipose tissue, left ventricular myocardial fat content, and interstitial fibrosis on myocardial contractile function. Circ Cardiovasc Imaging. 2018;11(8):e007372. https://doi.org/10.1161/CIRCIMAGING.117.007372

22. Bekar L, Kalçık M, Çelik O, Alp Ç, Yetim M, Doğan T, et al. Presence of fragmented QRS is associated with increased epicardial adipose tissue thickness in hypertensive patients. J Clin Ultrasound. 2019;47(6):345-50. https://doi.org/10.1002/jcu.22683

23. Yaman M, Arslan U, Bayramoglu A, Bektas O, Gunaydin ZY, Kaya A. The presence of fragmented QRS is associated with increased epicardial adipose tissue and subclinical myocardial dysfunction in healthy individuals. Rev Port Cardiol. 2018;37(6):469-75. https:// doi.org/10.1016/j.repc.2017.09.022

24. Lofgren I, Herron K, Zern T, West K, Patalay M, Shachter NS, et al. Waist circumference is a better predictor than body mass index of coronary heart disease risk in overweight premenopausal women. J Nutr. 2004;134(5):1071-6. https://doi.org/10.1093/jn/134.5.1071 